\title{
LAS FORTALEZAS EN LA DEFENSA DE LA HABANA (CUBA) A FINALES DEL SIGLO XVIII
}

\author{
JUAN DE ÁVILA GIJÓN GRANADOS \\ Departamento de Educação da Comunidade de Madri (Espanha)
}

\section{RESUMO}

O objetivo do trabalho é mostrar as grandes dificuldades que os responsáveis pela manutenção da administração espanhola enfrentaram no principal reduto do Caribe no século XVIII. A chave para a América espanhola é mostrada como um lugar com grande dinamismo, como visto nos detalhes da organização de suas tropas e sistema de proteção defensiva. A partir do arquivo de origem, rica documentação, artigo inédito espanhol centra-se no papel da administração do Capitão Geral e Governador de Cuba Havana Juan Procopio de Bassecourt (1740-1820), Conde II de Santa Clara. Através de seus esforços em defesa deste enclave comercial e militar importante é possível entender melhor as luzes e as sombras da administração espanhola no Caribe do Antigo Regime.

PALAVRAS-ChAVE: Fortalezas do século XVIII; administração espanhola no Caribe; Havana; Capitão General de Cuba.

\section{ABstract}

The aim of the paper is to show the great difficulties that those responsible for the maintenance of the Spanish administration clashed in the main stronghold of the Caribbean in the eighteenth century. The key to the Spanish America is shown as a place with great dynamism as seen in the details of the organization of its troops and defensive protection system. From the rich documentation source file Spanish unpublished article focuses on the role of the administration of Captain General and Governor of Cuba Havana Juan Procopio of Bassecourt (17401820), II Count of Santa Clara. Through his efforts in defense of this important commercial and military enclave can better understand the lights and shadows of the Spanish administration in the Caribbean of the Old Regime.

KEYWORDS: XVIII century fortresses; Spanish administration in the Caribbean; Havana; Captain General of Cuba. 
La posición estratégica de la isla de Cuba con respecto al Golfo de México destacó al puerto de La Habana como fundamental en el tránsito entre América y Europa. Parada obligatoria de la ruta entre España y el Nuevo Mundo se convirtió en el eje comercial de las posesiones americanas españolas. Desde el principio, los conquistadores, colonizadores o simplemente quienes desde España se fueron a "hacer las américas" fueron los que escribieron sobre aquella llave del Caribe y de toda América. La independencia de los territorios provocó el interés y el estudio sobre la realidad de sus respectivos países. En los años setenta, el estudio del Caribe se convierte en disciplina autónoma, surgiendo los investigadores caribeanistas, nativos y extranjeros, y la caribeanología, una especialidad dentro de los estudios de latinoamérica ${ }^{1}$. En la historiografía sobre el Caribe no ocupa un lugar destacado el análisis de este interesante aspecto de su defensa, considerado en este artículo, aunque son de sumo interés los clásicos estudios de J. M. Bens Arrate y otros, en los años cuarenta, y los más modernos de J. Aguilera Rojas, A. González Fernández o Tamara Blanes Martín. Esta investigación ha buceado entre noticias documentales de archivos para retratar la experiencia del gobernador Bassecourt al frente de su mandato a finales del siglo XVIII con especial observación hacia su sistema fortificado.

El conjunto de la ciudad vieja de La Habana y sus fortificaciones recibió en 1982 el título de Patrimonio de la Humanidad, por la UNESCO. Esta ciudad, fundada por los españoles en 1519, se convirtió en un importante astillero del Caribe en el siglo XVII. Sus fortalezas estaban presentes en el imaginario colectivo de San Cristóbal de La Habana hasta el punto de plasmarse en su emblema heráldico representativo de la ciudad. El escudo de La Habana tiene tres castillos y una llave que representan las fortalezas del Morro, la Punta y la Fuerza con la llave de la entrada a las Indias. El Castillo de la Real Fuerza se inició a mediados del siglo XVI después que unos corsarios franceses arrasaron la ciudad y, desde 1632, está coronada por la giraldilla, hermana de la existente en Sevilla. Para evitar incursiones piratas o flotas enemigas, se construyeron entre 1589 y 1630 el Castillo de los Tres Reyes Magos del Morro y la Batería de San Salvador de la Punta, ambos frente a frente en las dos márgenes de la entrada al puerto de La Habana.

Siendo la Villa de San Cristóbal de La Habana un lugar de paso de enormes riquezas de Asia y América en dirección a España, se tuvo gran esmero en fortificarla, convirtiéndola en una plaza fuerte de primera categoría que, en el siglo XVII, se comparaba con las famosas de Amberes, Milán o Pamplona. Dentro de la fortaleza del Morro había doce enormes cañones llamados "los doce apóstoles" ${ }^{\prime 2}$, los cuales parecían hacer la plaza inaccesible a un ejército enemigo

${ }^{1}$ CASTAÑEDA FUERTES, Digna. "Historiografía sobre el Caribe, continuidad e innovaciones durante los últimos veinte años", Tzintzun, Revista de Estudios Históricos, no 25, Universidad Michoacana de San Nicolás de Hidalgo, México, pp. 92-93, 1997. También es de interés: VENEGAS DELGADO, Hernán, "La historiografía regional y local en América Latina y el Caribe: una visión desde Cuba", Santiago, no 86, Universidad de Oriente, Santiago de Cuba, Cuba, pp. 533, 1999.

${ }^{2}$ Nueva relación que contiene los viajes de Tomás Gage en la Nueva España, París: Librería de Rosa, Tomo I, p. 260, 1838. [1ª edición 1699]. 
por gracia divina, aunque fue tomada por los ingleses en $1762^{3}$, en la que llamaron los habaneros "la guerra del inglés" ${ }^{4}$. Tras este insulto, el ingeniero Silvestre Abarca fue destinado a Cuba para realizar trabajos sobre las fortificaciones de La Habana (1763-1771) ${ }^{5}$.

Este punto clave fortificado tenía tanta importancia como Veracruz, Florida, Nueva Orleáns, Santo Domingo, Puerto Rico y algunos más en aquel momento en que el Tratado de Basilea entre Francia y España (1795) los hacía aliados y, por consiguiente, enemigos de los ingleses, cediendo Santo Domingo a Francia. El ejército de la monarquía vigilaba y controlaba la situación de estos enclaves especiales para la economía del reinado de Carlos IV. La isla de Cuba tenía dos gobernaciones: La Habana y Santiago de Cuba, situándose la Capitanía General de Cuba en manos del gobernador de La Habana. Tras el proceso de conquista y colonización americana, se iniciaba una etapa de lucha por mantener los dominios ultramarinos ante el peligro inminente de su pérdida ante otra potencia europea. El grado de desarrollo de las fortificaciones del Caribe hispano va ligado a la evolución de las armas de fuego y al arte de la poliorcética. Los ángulos muertos de los castillos medievales son sustituidos por los baluartes cuyos flancos y caras logran ángulos activos y polidireccionales. Durante los siglos XVI-XVIII, la monarquía asimilaba el sistema abaluartado adoptado por las escuelas de Italia, Países Bajos y Francia aplicándolo a las peculiaridades geográficas y a la singular estrategia defensiva de las colonias americanas.

El sistema de fortificaciones del conjunto de una plaza tenía como eje central la ciudad, y la organización de sus diferentes elementos defensivos, en combinación, hacían posible su existencia. El espacio interior de la fortificación se vuelve más dinámico, creciendo las vías de comunicación destinadas a los movimientos de tropas con una artillería heterogénea situada en diferentes niveles de altura. La ciudad fortificada se delimita con el campo a través de las murallas, que tienen puestos militares repartidos a distancia para evitar la invasión de la ciudad. Al pie de las murallas estará situado el "Campo de Marte" (glacis) que se utilizará para los ejercicios militares. En la isla de Cuba se fortificaron las bahías de Santiago de Cuba, Matanzas y La Habana. En la ciudad de La Habana los castillos de la Real Fuerza (1558), los Tres Reyes del Morro (1589) y San Salvador de la Punta (1590) defendían el puerto y en una extensa área de costa se repartían ingenios militares menores como Cojímar y Santa Dorotea de Luna de la Chorrera (1639), Bacuranao (1692), San Lázaro (1662) y el torreón de Marinarao (c1660). En el siglo XVIII se produce un perfeccionamiento de la artillería y se atrincheran las defensas apoyadas con sistemas de avanzadas. A partir de 1763, por la devolución de la plaza por los

\footnotetext{
${ }^{3}$ Sobre la ocupación inglesa ver: GARCÍA, Guadalupe. "Nuestra patria La Habana: Reading the 1762 British Occupation of the City", Nuevo Mundo Mundos Nuevos [En línea]. Debates, [http://nuevomundo.revues.org/61119; DOI: 10.4000/nuevomundo.61119].

${ }^{4}$ GARCÍA, José de Jesús de Q. "La guerra del inglés", Revista de La Habana, Imprenta del Tiempo, $2^{\mathrm{a}}$ serie, Tomo I, La Habana, pp. 19-26 (1856).

${ }^{5}$ VVAA., Los ingenieros militares en España. Siglo XVIII. Repertorio biográfico e inventario de su labor científica y espacial, Universitat de Barcelona, p. 24, 1983.
} 
ingleses, en La Habana se construyen tres fortificaciones modernas, como fueron el Castillo de San Carlos de La Cabaña, el Castillo del Príncipe y el Castillo de Santo Domingo de Atarés. La fortaleza de La Cabaña, por su magnitud, es comparable al Castillo de San Cristóbal (San Juan, Puerto Rico), al Castillo de San Felipe de Barajas (Cartagena de Indias, Colombia) o al de San Juan de Ulúa (Veracruz, México $)^{6}$.

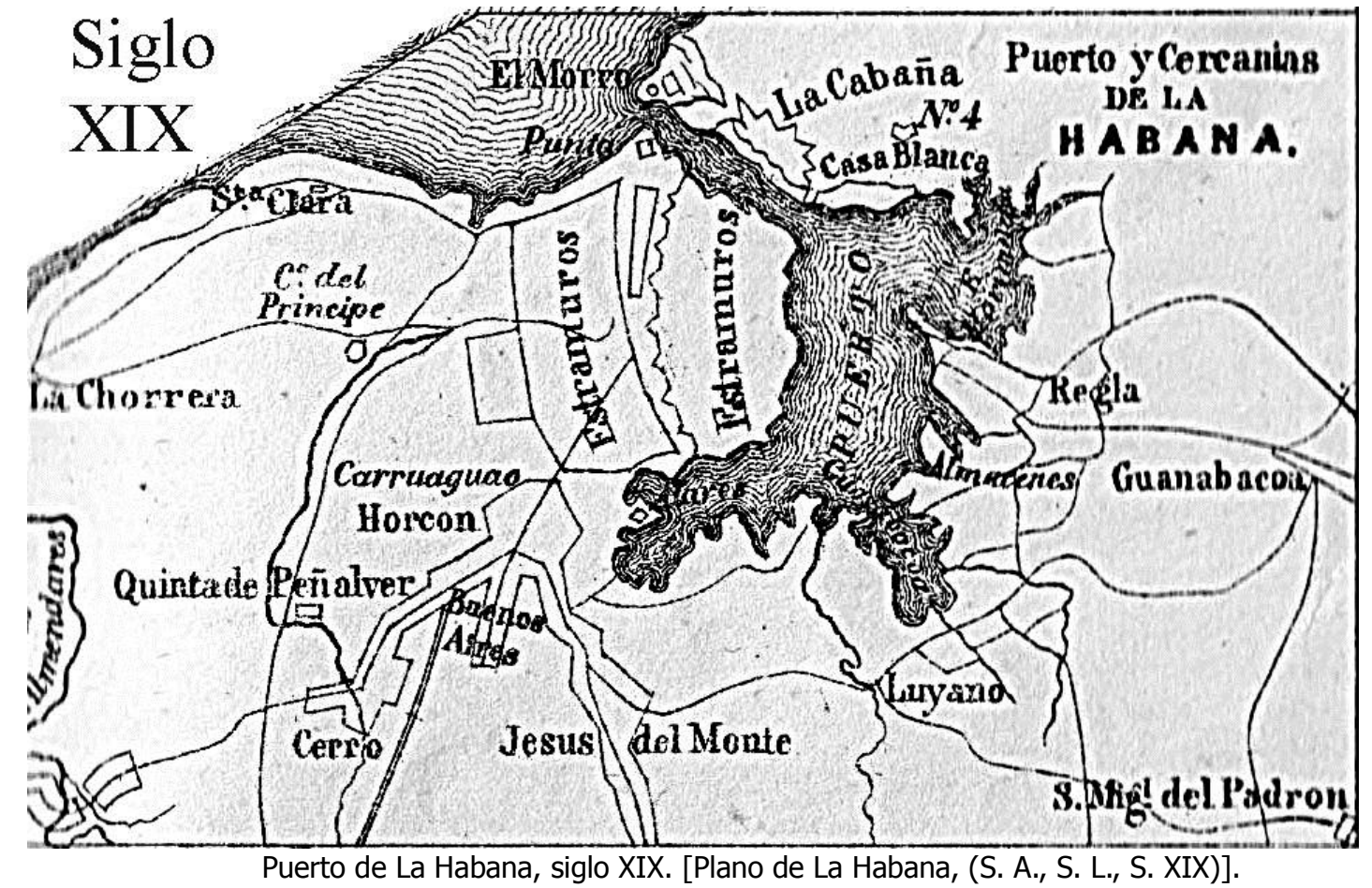

Estas fortalezas abaluartadas de estructura geométrica, simétricas y proporcionadas utilizaron las medidas matemáticas junto a técnicas constructivas con piedra labrada en sillares y mampostería, aunque también usaron el ladrillo para reforzar los ángulos de los muros, así como hierro y madera para obras complementarias de la fortificación. Unas fortalezas que defendían la costa con la imagen de un bello diseño de líneas y formas que buscaban la perfección. En esa arquitectura militar se combina la monumentalidad y la funcionalidad ${ }^{7}$. La etapa entre la devolución de La Habana por los ingleses y el inicio del proceso de independencia de las colonias hispanoamericanas tuvo una gran actividad en relación a las fortificaciones, que aseguraban la ciudad con las tropas españolas, en combinación con las milicias locales.

El Caribe quedaba muy lejos de la corte de Carlos IV en Madrid. Piratas, guerras y huracanes acecharon la tranquilidad de las islas, tanto con los Austrias como con los Borbones. Los días 21 y 22 de junio de 1791 hizo acto de presencia un catastrófico huracán en Cuba que entretuvo al gobernador de La Habana, Luis de Las Casas, en arreglar lo destruido. Él comenzó a realizar obras de reparo en

\footnotetext{
${ }^{6}$ BLANES MARTÍN, Tamara. Fortificaciones del caribe. Madrid: Letras Cubanas, p. 7-17, 2001.

${ }^{7}$ BLANES MARTÍN, Tamara. op. cit., p. 22.
} 
"las Puentes Grandes" en 1796, que terminaron con el siguiente gobernador, Conde de Santa Clara, en 1798 como "puentes del Mordazo" ${ }^{8}$. Además de estos temibles huracanes, el Caribe sufrió desequilibrios territoriales con el vaivén de los resultados de las guerras entre los países europeos. Los diferentes territorios políticos americanos podían ser, según la fecha, aliados, neutrales o enemigos. Estos se ganaban, se perdían, se sublevaban y hasta se compraban, lo que dificultaba la relación entre ellos y la organización de sus gobernaciones. Ya en 1777, Bernardo de Gálvez, gobernador de Luisiana, escribía a Joseph de Gálvez, secretario de Estado y del Despacho Universal de Indias, para hacerle ver que no existían buques que llevaran correo desde La Habana a Nueva Orleáns ${ }^{9}$, capital de La Luisiana. Debió ponerse a punto este servicio a continuación porque tenemos documentación de correo entre ambos lugares desde 1784 a $1810^{10}$. También existía el peligro de la captura del correo, así tenemos noticias de cómo la goleta correo "La Santísima Trinidad" fue apresada por la fragata inglesa "Melpomene" en febrero de 1797. Su destino era Puerto Rico, aunque terminó presa en Kingston (Jamaica) ${ }^{11}$. El mismo año también era apresada la goleta correo "La Liebre" por la balandra inglesa "La Isabela". Esta goleta correo daba servicio entre Nueva Orleáns y La Habana. Su capitán Antonio de Acosta tuvo la habilidad de tirar al agua el "caxon" con la correspondencia antes de que los ingleses subieran a bordo ${ }^{12}$. Sin duda, entre la correspondencia oficial había datos sobre las obras de las fortalezas y la situación de las guarniciones de aquellas plazas. La delicada información no debía caer en manos del enemigo que miraba la plaza de La Habana con gran interés.

El responsable de aquellas fortalezas de La Habana enviaba una carta desde Cádiz, en agosto de 1796, a Manuel Godoy informándole que no podía tomar posesión del cargo de Capitán General de Cuba y Gobernador de La Habana porque no había ningún buque que le llevase a su destino ${ }^{13}$. Finalmente, entre diciembre de 1796 y mayo de 1799, sucedía a Luis de las Casas el nuevo capitán general Juan María Procopio de Bassecourt y Bryas (1740-1820), caballero de la Orden de Santiago ${ }^{14}$, Barón de Mayals ${ }^{15}$ y II Conde de Santa Clara, que tomaba posesión en enero de 1797, después de cuatro meses de espera mirando el horizonte en Cádiz. La carrera de este militar de las Reales

\footnotetext{
${ }^{8}$ VALDÉS, Antonio J. Historia de la Isla de Cuba y en especial de La Habana. Habana, Oficina de la Cena, vol. I, p. 215, 1813.

9 "Hace presente el perjuicio que causa de no tener S. M. buques destinados que hagan de correos desde la Havana a ella y las ventajas que se pueden sacar del establecimiento de uno o dos a este fin". Archivo General de Indias, Santo Domingo, 2.547.

${ }^{10}$ Correspondencia de las autoridades de España y la Habana con las de La Luisiana y Florida. Memoriales diversos. AGI. Cuba. Legajo 105. 1782-1810.

${ }^{11}$ AGI. Estado, 1, no 5.

${ }^{12}$ AGI. Estado, 1, no 85.

13 Carta del Capitán General de la Habana, Conde de Santa Clara, al Príncipe de la Paz, participándole hallarse todavía en Cádiz, por falta de un buque que le conduzca a su destino. AGI. Estado. 5B, no 183.

${ }^{14}$ Hábito de la Orden de Santiago, 1751. Archivo Histórico Nacional. OO. MM. Expedientillos no 17.517.

${ }^{15}$ Concedido en 1754. AHN. Consejos, L. 2.371, fol. 136.
} 
Guardias Walonas y teniente general de los Reales Ejércitos había pasado por los gobiernos de Ceuta, Gerona y Barcelona. Él estuvo mandando el Ejército de la Derecha en las operaciones en Cataluña, de la Guerra de la Convención (17931795); desempeñó varias misiones con la confianza de grandes generales, como Luis Fermín Carvajal, Conde de la Unión, y el ingeniero José de Urrutia, siendo enviado a la Gobernación de La Habana mientras pedía por sus méritos militares "una encomienda de las medianas o pequeñas", para él y su sobrino Andrés de Bassecourt, alférez de las Reales Guardias Walonas ${ }^{16}$.

Al llegar a la isla, su principal interés fue observar en que estado recibía las defensas de la plaza de La Habana y sus fortificaciones cercanas. Después de vistas, el mando militar opinaba que necesitaban algunas reparaciones urgentes. Le acompañaba en esta labor a un teniente de artillería e ingeniero, más algunos oficiales que entendían de la materia. Debía tener grandes conocimientos en el arte de la poliorcética, puesto que, no olvidemos, había servido con el ingeniero José de Urrutia (comandante general del Real Cuerpo de Artillería, en 1799). No perdía el tiempo en su trabajo y organizó mejor las defensas de La Habana. El nuevo capitán general era descendiente de una familia europea (Flandes), de linaje militar, que había anclado su destino al servicio de la corte española, disfrutando del privilegio de ser caballero de la Orden de Santiago y de Carlos III. Desde allí, el gobernador de La Habana y capitán general de Cuba pedía por carta (1797) a Manuel Godoy que se diera a su esposa María Teresa de Sentmanat, como merced, la concesión de la banda de la Orden de Damas Nobles de María Luisa ${ }^{17}$. Ella desarrollaría labores humanitarias en La Habana ganando apoyo para su marido.

Pese a que el anterior gobernador, Luis de las Casas, era muy querido por la población, pronto superó Bassecourt por sus buenas relaciones con todo tipo de vasallos de diferentes clases. Una publicación de 1813 señalaba que:

...se dedicó a reparar y extender las obras de fortificación de la plaza, construyendo el foso y camino cubierto del recinto de la ciudad, e hizo edificar entre San Lázaro y la Chorrera, la batería conocida con el nombre de Santa Clara en memoria de su fundador: y los cuerpos de que se componía esta guarnición de esta plaza fomentaron en aquel tiempo cierto entusiasmo militar, que sabía infundirles su General ${ }^{18}$.

Este personaje, que después ejercería como Capitán General de Cataluña, apreció que las murallas y fortalezas defensivas de la plaza de La Habana estaban muy abandonadas y no eran garantía en caso de ataque enemigo ${ }^{19}$. Esas murallas surgieron como consecuencia del ataque pirata del francés Jacques

\footnotetext{
${ }^{16}$ AGI. Estado, 1, no 29. Aunque a su sobrino le negaron el hábito de la Orden de Santiago por faltarle tres años de servicio para poder obtenerlo, puesto que debía tener ocho años de servicio (Real Decreto, 30 octubre 1773). Carta al Capitán General de Cuba, 1797. AGS. SGU. Leg. 6.859, 37.

${ }^{17}$ AUTOR, 2011, p. 186.

${ }^{18}$ VALDÉS, Antonio J. op. cit., p. 229.

${ }^{19}$ Archivo General de Simancas. SGU. LEG. 7.244, 24. "Estado fortificaciones y tropa La Habana", 1797.
} 
Sores, en 1555, y debido a los fuertes desembolsos por su gasto tuvo varias etapas de construcción. A la altura de 1680 aun no se había construido nada más que la mitad; y en 1719 se iniciaron las tareas para su conclusión ${ }^{20}$, que finalizaron en $1740^{21}$. Las cosas de palacio iban despacio, pero además se detectó un defecto: y es que los baluartes eran "baxos", ya que no estaban situados en las partes más altas de la ciudad. Esto se debía a que se habían construido en otra época en que el arte de la poliorcética no estaba tan desarrollado como a finales de la centuria del XVIII. El jefe militar de la plaza echaba de menos fosos, revellines, caminos cubiertos o simples explanadas para defender a los puestos militares. Elementos defensivos, que en su mayor parte eran sencillos de realizar, estaban para ser utilizados como defensas pasivas ante un intento de invasión enemiga. A mediados del siglo, el gobernador Conde de Revilla-Gigedo había dado orden de demoler en una huerta sus edificios para construir un nuevo arsenal (1739), pero se había quedado el lugar arrasado por estar el terreno arrimado a las murallas de La Habana y "por hallarse bajo del cañón de la muralla de aquella plaza". En 1767, los herederos de Francisco González del Álamo se quejaban que les habían quitado el terreno para realizar un arsenal y, finalmente, no se había construido nada. Lo cierto es que "el derribo [era] necesario, para que aquella [plaza] estuviese en estado de defensa". Se determinaba como un acto beneficioso y se usaba la certificación técnica del ingeniero Juan de Cotilla que justificaba la demolición por distar menos de un tiro de fusil desde las murallas, poniendo en estado de defensa la plaza, como prevención a un ataque de una expedición inglesa enemiga. Finalmente se señalaba que:

...el derribo de estas fábricas no tuvo otro objeto que el de la mayor seguridad de la plaza, respecto del paraje prohibido, en que estaban plantificadas, en lo cual también eran particularmente interesados los habitantes de ella.

La documentación también señala que fueron varios los edificios que se determinaron derribar en diferentes puntos porque, según la legislación, si hubiese una vivienda alrededor de un castillo, muralla o fortaleza a menos de 300 pasos, se debía demoler pagando un importe económico por perjudicar al propietario ${ }^{22}$.

\footnotetext{
20 SANZ CAMAÑES, Porfirio. Las ciudades en la América Hispana. Siglos XV al XVIII. Madrid: Sílex, p. 273, 2004.

${ }^{21}$ DE LA TORRE, José María. Lo que fuimos y lo que somos o La Habana antigua y moderna. La Habana: Imprenta de Spencer y Compañía, p. 20, 1857.

${ }^{22}$ AHN. Códices, L756, fols. $295 r^{\circ}-298 r^{\circ}$.
} 


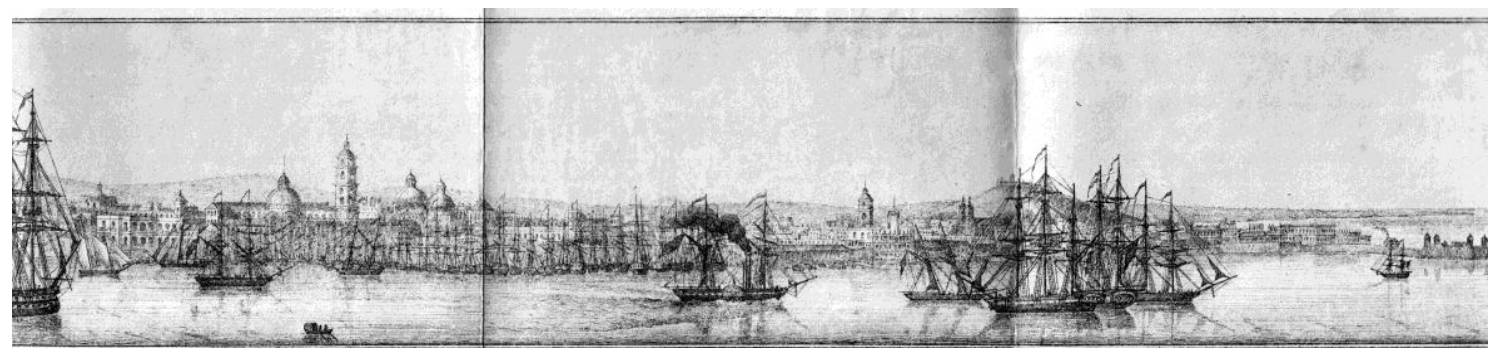

Vista de La Habana. [Plano de La Habana, (S. A., S. L., S. XIX)].

El crecimiento demográfico había hecho aparecer los arrabales de Jesús María, Horcón, Guadalupe y San Lázaro. Los tres primeros estaban muy desarrollados con edificios pobres, entre los que existían algunos de mampostería cubiertos de guano. Y si un ejército enemigo invadía la zona, les resultaría de gran importancia usar esas viviendas domésticas como abrigo del fuego defensivo de la plaza. De especial importancia eran dos edificios que habían quedado construidos demasiado lejos del centro urbano. Cerca del barrio de Jesús María se hallaba la Real Factoría de Tabacos y el Arsenal (unido a la muralla). Una simple obra de trincheras defendería estos edificios de un golpe de mano ante el enemigo, pero esta defensa no se había pensado nunca. Pocos años después, un terrible incendio (1802) en estos barrios afectó a unos 6.000 vecinos y en donde "...se abrasó un considerable número de habitaciones". Este fenómeno se produjo por la combinación del fuerte viento y el guano de los tejados ${ }^{23}$.

El Castillo del Príncipe se describía como "pequeño, sus baluartes, cortinas, flancos y revellines diminutos y el glasis no está acavado". Por lo que lo primero que realizaron fue despejar una zona alrededor de la fortificación (glacis) para poder defenderse desde dentro con mayores garantías, dado que la aparición de casas y otros elementos facilitaban la proximidad de un enemigo parapetado. El Castillo de Atarés tenía una ubicación magnífica porque lo rodeaba el mar y un foso ("una zanja profunda zenagosa"). También se dieron órdenes de desalojar todos los elementos cercanos a esta fortificación para que no sirvieran de parapeto a una posible llegada de enemigos. La ley obligaba a no poder construir en las 300 varas alrededor de castillos o murallas y el ingeniero Silvestre Abarca, en 1765, aplicaba una nueva ley (1764) que aumentaba a 1.500 varas el espacio a respetar, por lo que se demolieron edificios ${ }^{24}$. Pero los problemas de la vida en la ciudad no solamente giraban en torno a sus defensas. Durante el mandato del nuevo gobernador Bassecourt, el nombramiento del capellán de la capilla del Castillo del Príncipe, José Morejón, fue objeto de disputa jurídica entre el obispo de La Habana, Felipe J. de Trespalacios, y el Conde de Santa Clara ${ }^{25}$.

Las fortalezas del Morro y de la Cabaña solo necesitaron pequeñas reparaciones que se realizaron con rapidez. La fortaleza de San Carlos de la

\footnotetext{
${ }^{23}$ AGI. Estado, 2, no 32.

${ }^{24}$ DE LA TORRE, José María. op. cit., p. 44-45.

${ }^{25}$ Competencias entre el capitán general de Cuba, conde de Santa Clara y el obispo de La Habana, Felipe José de Trespalacios para el nombramiento que ha hecho este último de capellán de la capilla del Castillo del Príncipe de La Habana, en José Morejón presbítero. 1798. AGS. SGU. Leg. 6.862, 23.
} 
Cabaña era la de mayores dimensiones, construida por los españoles en América. Para reforzar su potencial, se restablecieron algunos fortines abandonados que fueron mejorados para defender el conjunto, tales como un fuerte (avanzada $n^{\circ}$ 4, o "San Diego") y el Bonete (reducto $n^{\circ} 3$ ). Estos tenían arruinados sus "parapetos, embrasuras y merlones". Se trataba de los dos puntos desde donde se podía iniciar un ataque contra el complejo militar de la Cabaña y por ello detendrían a una tropa enemiga al desembarcar.

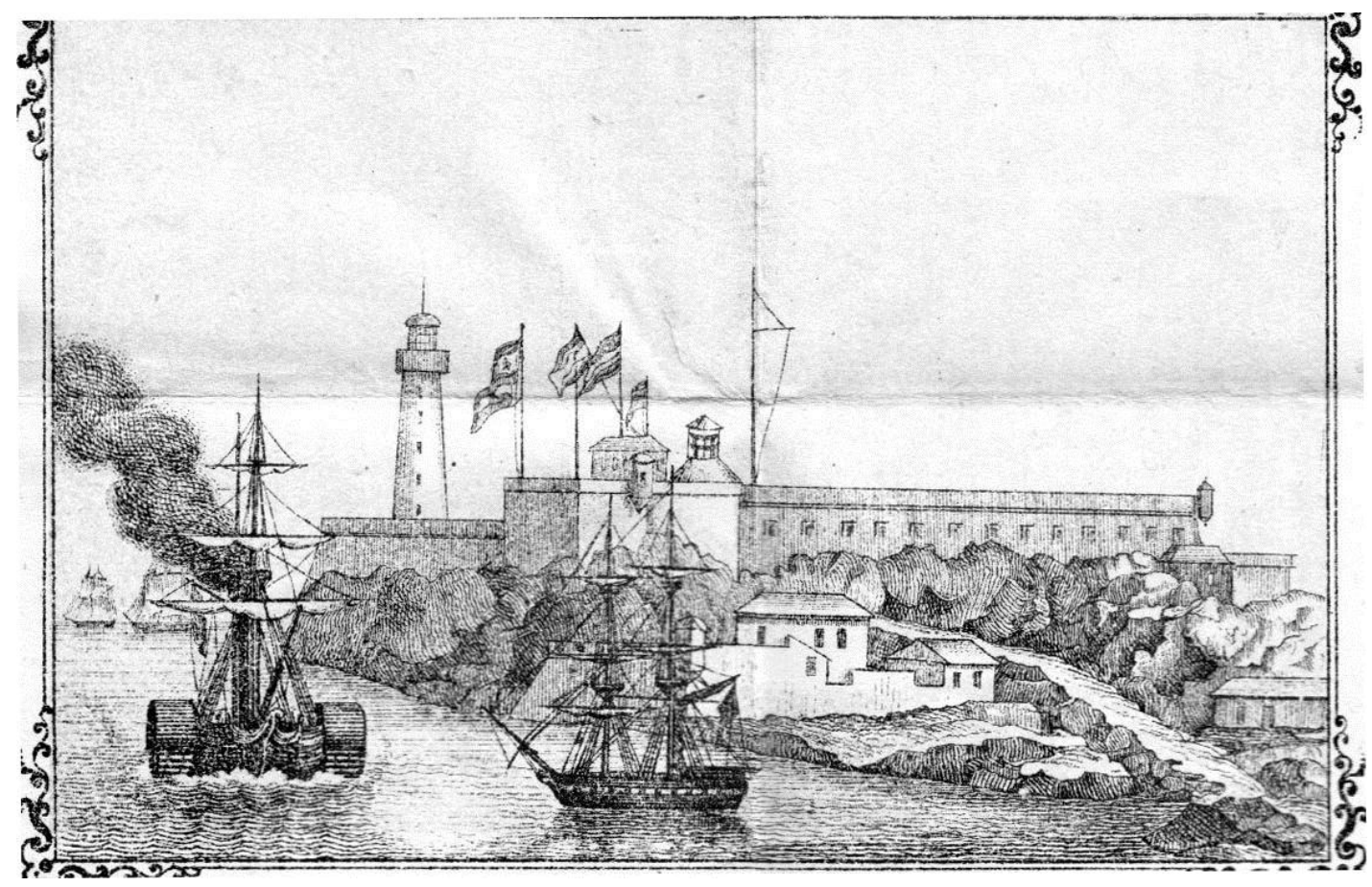

Castillo del Morro, La Habana. [Plano de La Habana, (S. A., S. L., S. XIX)].

El puerto de Cojímar, donde habían desembarcado las tropas inglesas en 1762 durante la Guerra de los Siete Años, tenía un torreón abandonado que fácilmente podría albergar cuatro cañones de mediano calibre, o dos "de calibre $16^{\prime \prime}$, para dificultar la llegada de enemigos por esta parte, que era la más sencilla para desembarcar, por ser un tramo corto y llano para acceder a las fortalezas de la Cabaña y del Morro.

En 1750, el gobernador de Jamaica, Charles Knowles, recopilaba información de manera secreta para los ingleses, aprovechando una visita a La Habana y preparando un ataque. Informaba a Londres de la gran dificultad de su conquista siempre que las defensas del Castillo del Morro estuvieran activas. Precisamente, doce años después, los ingleses vencían a los españoles a partir de la clave que dio Knowles, de acabar con la fortaleza del Morro aprovechando la colina de la Cabaña, desde donde tomaron el resto de la ciudad ${ }^{26}$. Algo debieron olerse los españoles, ya que hicieron primitivas fortificaciones para tratar de

${ }^{26}$ SANZ CAMAÑES, Porfirio. op. cit., p. 274. 
defender esa posición, con prisas. Precisamente el ingeniero Francisco Ricaud había levantado un plano en 1761 sobre "el nuevo castillo de San Carlos en la Cabaña, La Haband ${ }^{\prime 27}$, aunque el proyecto no se había realizado cuando llegaron los ingleses. La enorme fortaleza de la Cabaña se erigió para evitar que los ingleses pusieran su artillería de nuevo en ese lugar para rendir la fortaleza del Morro. Aquella fue la clave de la conquista de la ciudad y de los nueve meses que perteneció a los ingleses. Poco después ellos la intercambiaron por parte de la Florida, en 1763.

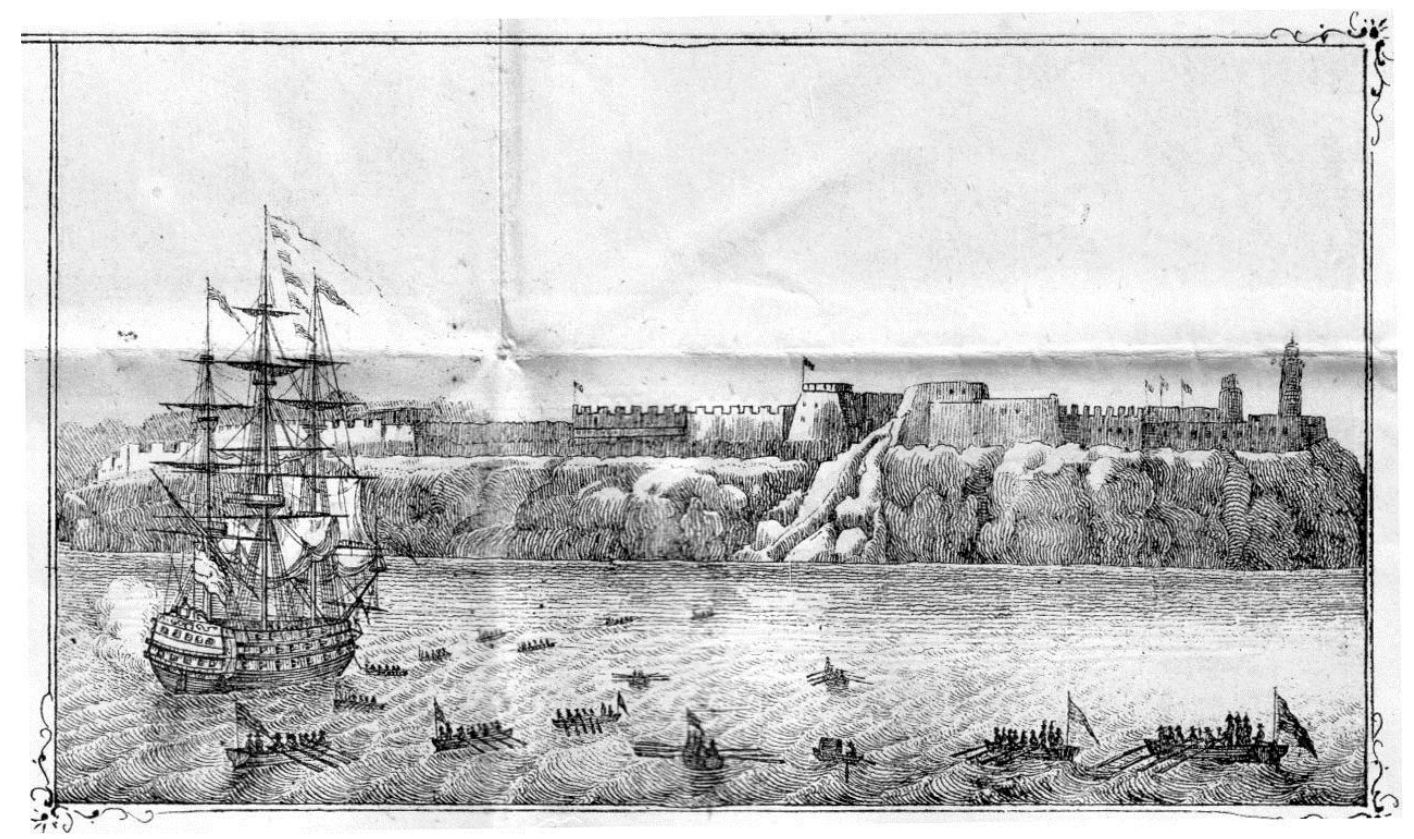

Asalto al Castillo del Morro por los ingleses en 1762. [Plano de La Habana, (S. A., S. L., S. XIX)].

A una legua estaba la Batería de Bacuranao, de mampostería, pero abierta por la gola y mal construida con parapetos de poca altura. Desde allí y a través de claros del bosque, tropas enemigas podían dirigirse a Guanavacoa y Pueblo de Jesús del Monte hasta La Habana, evitando la artillería del Fuerte de Atarés. Por ello el nuevo, responsable de la defensa de La Habana, pensaba inutilizar los caminos para dificultar esta posibilidad, situando pequeñas tropas en diferentes parajes si tuviese la posibilidad de contar con suficiente guarnición. Estudiaba el itinerario de las potenciales tropas invasoras para dificultar su avance al interior de la isla.

El río de la Chorrera no podía vadearse en su desembocadura y un ejército debía penetrar unos 650 metros a tierra firme para cruzarlo. Existía un torreón con capacidad de cuatro cañones de grueso calibre y cuatro obuses (el cañón dispara recto y rasante, el obús tiene tiro curvo), por lo que el nuevo responsable dispuso se habilitase de tal forma para evitar que un enemigo realizase una aguada, como hicieron los ingleses en 1762 para tomar la plaza. También volvió la escuadra inglesa, en 1782, a realizar otra aguada en este punto

${ }^{27}$ VVAA. op. cit., p. 398. 
donde solo quedaban los restos de la antigua torre mirando al mar. Al militar le parecía una broma que las tropas inglesas pudieran parar en Cuba para abastecerse de agua. La Junta de Guerra realizaba esta obra de la antigua Torre de la Chorrera (Real Decreto de 1795), convirtiéndola en un fuerte más consistente y el nuevo gobernador estudiaría las obras necesarias para la defensa de las murallas. No era una situación diferente de la que encontró el militar Antonio Olaguer Feliú, virrey del Río de la Plata, en 1797. Sus principales fortalezas se hallaban sin artillería, con poca dotación, faltos de obras básicas y hasta algún fuerte sin puerta ${ }^{28}$. Ambrosio O'Higgins, presidente de la Audiencia de Chile, escribía a Manuel de Negrete y de la Torre, Conde de Campo Alange, Secretario de Guerra, contándole los mismos problemas (1792) en las fortificaciones de Valparaíso (Chile) ${ }^{29}$. Parece que los responsables de las plazas fuertes americanas tomaban posesión, arreglaban lo que podían y, cuando eran sustituidos los siguientes, se encontraban en una situación similar.

Aquellas fortificaciones abaluartadas no protegían solas las plazas americanas. Las tropas que defendían La Habana estaban divididas entre su guarnición (cuerpos fijos) y algunos de los destacamentos del ejército de la monarquía en la zona que custodiaban este estratégico enclave. Normalmente una ciudad costera tenía una guarnición estable y una milicia voluntaria para situaciones de emergencia, pero La Habana era un punto clave en el Caribe - de ahí su tratamiento especial con una combinación de fuerzas armadas más la opción de utilizar las milicias en momentos de crisis. Las cifras de soldados destinados en aquel momento a La Habana sumaban 1.364 militares de guarnición (881 en servicio real) y 1480 militares del Primer Batallón de México, el Regimiento de Puebla, Partida de Nueva España y Partida de Cantabria (722 en servicio real). Oficialmente entre la tropa de guarnición debía haber 1603 veteranos para defender la plaza y sus castillos. De los 881 que realmente existían para el servicio de la defensa de la plaza había 227 que descontar, porque 66 miembros del Escuadrón de Dragones eran utilizados para llevar documentación oficial y escoltar los caudales dentro de la isla, más otros 161 del cuerpo de artillería ubicados para cuidar los almacenes de pólvora, la artillería y sus castillos. Restaban 654 de los que había que quitar también otros 127 de las Compañías de Infantería Ligeras que guardaban los fuertes del Morro y Atarés. Además había que descontar otros 191 denominados "ausentes ultramarinos", presos y enfermos. Algunos soldados disfrutaban de permiso en lugares como las islas Canarias, Puerto Rico, Santo Domingo, Nueva Orleáns, México y Florida. Dadas las dificultades, se había dispuesto tropa para defender La Habana en combinación a su guarnición. El Regimiento de Puebla estaba al servicio de la plaza; el Batallón de México guardaba la fortaleza de la Cabaña, la Batería de San Diego ( $n^{\circ} 4$ ), el Castillo del Príncipe, cuatro almacenes de pólvora y la Batería de Batabanó (a 14 leguas). Otros estaban embarcados en la escuadra del puerto (63 de guarnición, 579 de las tropas) y algunos más, enviados a las fortalezas de

\footnotetext{
${ }^{28}$ Estado de las fortalezas de D. Antonio Oleguer. AHN. Diversos-Colecciones, 31, no 101.

${ }^{29}$ Informa sobre el estado de las fortalezas de Valparaíso y sugiere las obras más principales y urgentes para asegurar su defensa. AGI. Chile, 198, nº 54.
} 
Matanzas y Jagua. En octubre de 1776, Luis de las Casas había enviado una carta a Manuel Godoy dando órdenes al Gobernador de Cuba y a los comandantes de las fortalezas de Matanzas y Jagua para estar en alerta por la sospechas de la llegada de la armada inglesa ${ }^{30}$. Debió ser en ese momento cuando se enviaron algunos oficiales y soldados ${ }^{31}$.

Con cierta ironía, el gobernador Bassecourt afirmaba que en este estado la guarnición no aguantaría "una noche buena" (una navidad) y tampoco se decidía a poner milicias por no repartir armas a la población civil mientras no fuese una situación de urgencia. El problema social de los voluntarios era que si se les obligaba a realizar guardias, no trabajaban en sus oficios y ocupaciones familiares. Pedro José Guiteras, en el siglo XIX, señalaba que las primeras milicias que colaboraron en la defensa de La Habana fueron en tiempo del Gobernador Álvaro de Luna (1639-1647) y se ubicaron en dos torres que defendían las desembocaduras de los ríos Chorrera y Cojímar $^{32}$. De los dos regimientos del ejército de Nueva España, tan solo había esta tropa dispuesta, porque el Segundo Batallón de México se encontraba en Nueva Orleáns (capital de La Luisiana) - Puebla tenía la mitad de su fuerza en la escuadra y la Partida de Nueva España estaba en la escuadra de este puerto. A ello debemos sumar que el Escuadrón de Dragones de América, tropa fija de La Habana, realizaba labores internas muy diferentes de las que debía realizar, convertidas en la práctica en una especie de policía de seguridad, protectores del correo militar y escolta de los caudales públicos. A esta función debemos añadir que dirigía el cuerpo el Coronel José Valverde, comandante del Escuadrón de Dragones de La Habana, que llevaba 62 años desde cadete en el ejército, habiendo participado en las guerras de Italia y en la expedición a La Luisiana. El capitán general pensaba que este militar merecía "un honor o retiro por sus largos servicios y hallarse cansado, pues por su edad avanzada (es de 75 años), cortas luces y ninguna disposición carece de la necesaria para mando". A lo que había de añadir que el teniente de rey de la plaza de Cuba era un brigadier de 80 años que servía interinamente ${ }^{33}$. Según la opinión del militar, las milicias de La Habana harían un buen papel en un hipotético asedio, puesto que había visto maniobrar a los dos batallones del Regimiento de Infantería, a los dos "batallones de pardos y morenos" y al Regimiento de Caballería, siendo de gran satisfacción ver lo bien dirigidos que estaban por sus oficiales, especialmente "los blancos de infantería y caballería". Los hombres de las milicias no eran tan aguerridos como los veteranos (profesionales) por la falta de experiencia en la lucha.

\footnotetext{
30 "Carta muy reservada del Gobernador de la Habana, D. Luis de las Casas, al Príncipe de la Paz, dando cuenta de haber recibido un oficio muy reservado sobre próximo rompimiento con los ingleses, y de haber dado aviso al Gobernador de Cuba y a los Comandantes de las fortalezas de Jagua y Matanzas para su vigilancia". AGI. Estado, 5B, No 192.

${ }^{31}$ Concretamente, eran once oficiales y 46 soldados de la Compañía de Infantería Ligera, más un sargento, un cabo y siete soldados del cuerpo de artillería que pertenecían a la guarnición fija de La Habana y cinco oficiales y 14 soldados del Regimiento de Puebla. Todos se destinaron a aquellos dos fuertes. AGS. SGU. Leg. 7.244, 24, fol. 14 ro.

32 GUITERAS, Pedro José. Historia de la conquista de La Habana (1762). Filadelfia (EE. UU.): Parry and McMillan, p. 53, 1856.

${ }^{33}$ AGS. SGU. Leg. 6.877, 23, fol. $8 \mathrm{r}^{\circ}$ y $11 \mathrm{v}^{0}$.
} 
La población original insular había desaparecido por los problemas epidémicos y los enfrentamientos bélicos. Esto había hecho traer población africana que, junto a la europea, había dado como consecuencia la aparición de mulatos. La isla estaba habitada por hombres de raza blanca que sumaban más que el resto, mulatos y negros. Con un crecimiento del 3\% anual, había en 1790 unos 260.000 habitantes en la isla. Siendo la población de La Habana y sus arrabales (1791) de unos 24.000 de raza blanca, 5.400 mulatos libres, 4.500 negros libres, 500 esclavos mulatos y 17.000 esclavos negros, que sumaban unos 51.400 habitantes en La Habana ${ }^{34}$.

Pese a los controles que se tenían sobre la situación de las fuerzas de los territorios americanos, no parece que se tomaran apenas medidas al respecto ${ }^{35}$. Determinaba el gobernador Conde de Santa Clara que el número de soldados de tropa que necesitaba para guardar La Habana de una invasión era de 9.250 hombres, muy lejos de unos tres millares de militares que oficialmente debía haber para su defensa y de la dura realidad que encontró, al analizar la guarnición. En la práctica, apenas un millar vigilaba el horizonte del océano Atlántico en la plaza clave del Caribe. Así se lo hacía saber al Ministro de la Guerra Miguel José de Azanza (después Virrey de Nueva España, 1798-1800). El Duque de Santa Fe recogía la información facilitada por el gobernador Bassecourt y el propio Carlos IV, en el Palacio de Aranjuez, quedaba enterado de la necesidad de una mejor defensa de sus leales vasallos, en mayo de 1797. El rey resolvía que se hicieran las obras necesarias de manera urgente ya que "no hay razón que disculpe estos gastos" y su real voluntad era satisfacer la buena disposición para el trabajo del capitán general, aunque del contingente militar necesario no decía ni una palabra.

En junio de 1797 el gobernador Bassecourt afirmaba que, habiendo tratado en Juntas de Fortificación las costosas obras de defensa de la plaza, se acordó reforzar la parte que daba al interior de la isla (tierra) puesto que la de costa (mar) era suficiente. Así se desarrollaron las obras de creación de foso y camino cubierto "con el mayor vigor y ahorro de la Real Hacienda" puesto que los propietarios de esclavos de La Habana habían cedido gratuitamente el trabajo de estos para desarrollar la obra. Sin embargo, el geógrafo Humboldt señala el coste de la obra de "la muralla y el antiguo camino cubierto" de La Habana en 700.000 pesos fuertes ${ }^{36}$. Al mismo tiempo que Bassecourt reforzaba las fortificaciones, buscaba "brazos de defensa", puesto que tenía noticias de la inminente llegada de los ingleses $y$, por sus conocimientos militares, sabía que necesitaba más soldados para la defensa de La Habana. Ejecutó un plan para alistar en la ciudad

\footnotetext{
${ }^{34}$ VV. AA. Historia de la Nación Cubana. La Habana: Editorial Historia de la Nación Cubana, Tomo II, Libro Primero, p. 88, 1952.

${ }^{35}$ Documentación de 1790 señalaba la situación de la guarnición de La Habana. "Cartas reservadas que con esta fecha remite el Brigadier don Esteban Miró, Gobernador e Intendente de la Provincia de la Luisiana y Florida Occidental, al Excmo. Señor don Pedro López de Lerena, Secretario de Estado y del despacho universal de Hacienda. № 30.- Remite estados de fuerza del Regimiento fijo. La Habana". AGI. Santo Domingo, 2.554.

${ }^{36}$ HUMBOLDT, Barón A. de. Ensayo político sobre la Isla de Cuba. París: Casa de Jules Renouard, p. 15, 1827. Quizás tenía estos datos porque visitó La Habana en 1800.
} 
y su partido a todos los hombres entre 17 y 50 años formando "compañías provisionales urbanas de catalanes, vizcaínos, navarros y asturianos que se ejercitan diariamente en el manejo del arma". Parece que también se hacía con parte de los jóvenes menores de 17 y con otros mayores de 50 capacitados para la defensa. También agregó 24 voluntarios de caballería al Escuadrón de Dragones de América y otros 200 de infantería se les estuvo enseñando artillería. El entusiasmo de la población ante las dificultades hacía confiar al gobernador en tener "esperanza de poder hacer una vigorosa y dilatada defensa, si el enemigo intentare atacar esta plaza". La mayoría de los vecinos de La Habana ofrecieron, de forma fervorosa y en tan extraordinarias circunstancias, todos sus bienes al servicio de la defensa. Los fieles vasallos, sus hijos, sus esclavos y sus haciendas se ponían a disposición de Carlos IV a través del Gobernador. Un total de 340 reses y 25 caballos se ofrecieron para el servicio del puerto y 326 esclavos trabajaron para las obras de las fortificaciones ${ }^{37}$. La abundancia de mano de obra esclava de raza negra refleja la entrada clandestina constante de barcos negreros de manera ilegal que vendían en La Habana y otras partes de la isla ${ }^{38}$. La población de todo tipo y condición arrimaba el hombro en la defensa de la plaza de La Habana.

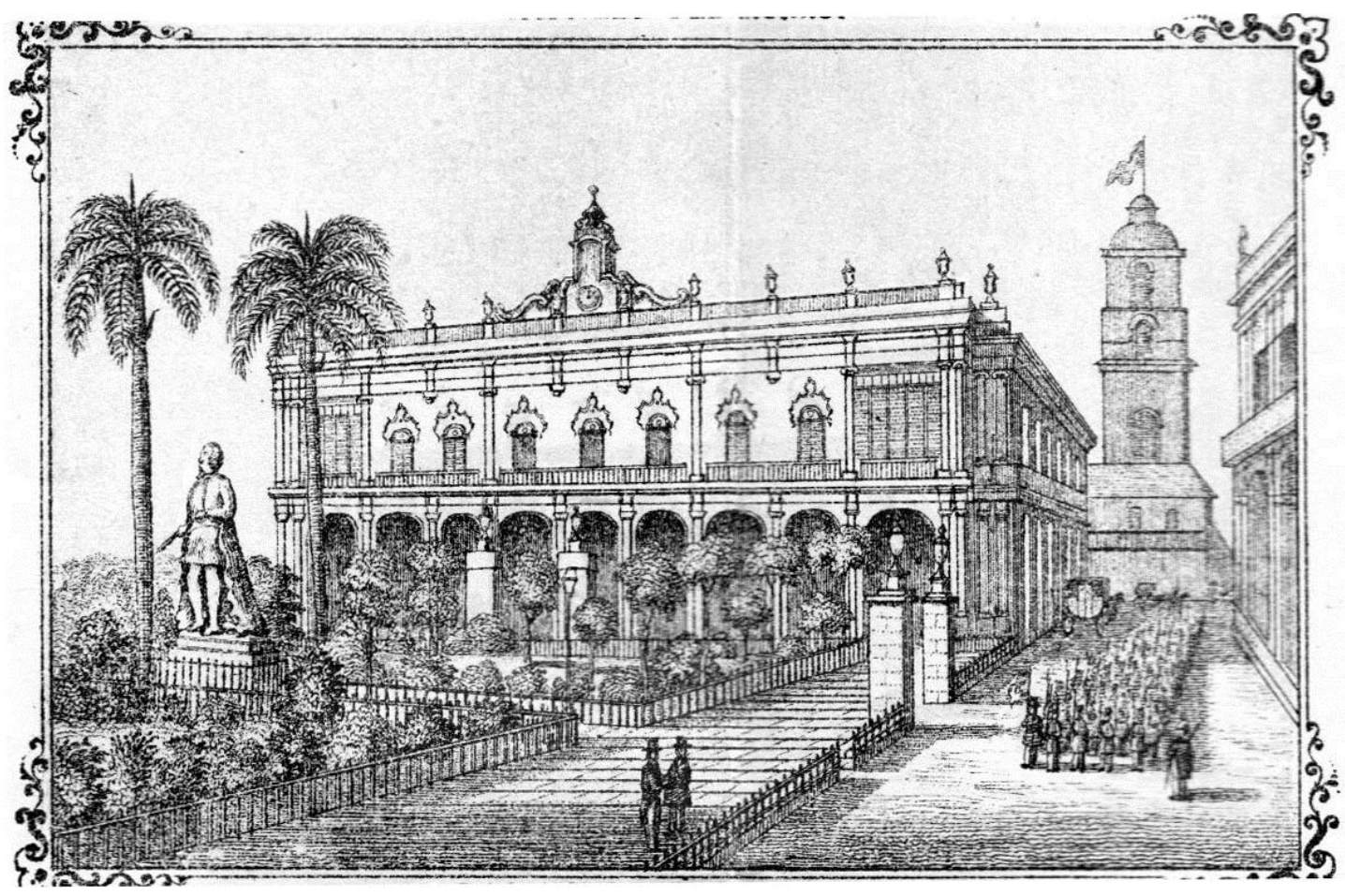

Palacio del Gobernador de La Habana. [Plano de La Habana, (S. A., S. L., S. XIX)].

\footnotetext{
${ }^{37}$ AGI. Estado, 1, no 23.

${ }^{38}$ NARANJO OROVIO, Consuelo. "La amenaza haitiana, un miedo interesado: Poder y fomento de la población blanca en Cuba", El rumor de Haití en Cuba: Temor, raza y rebeldía, 1789-1844. Madrid: CSIC, p. 105, 2005.
} 
Por si acaso tenía poco que hacer, el gobernador de Cuba recibía el nombramiento interino en La Luisiana y Florida (junio, 1797), mientras el embajador español en los Estados Unidos le informaba desde Philadelphia (Massachussets) de las intenciones de los ingleses de atacar La Luisiana ${ }^{39}$. Entre sus tareas estaba:

...excitar el estado de Kentucky a que se separase de la Unión Federal tratando este asunto con varios sujetos notables de dicho estado, con el mismo [Brigadier Jaime] ${ }^{40}$ Wilkinson y generalmente con todos en sus conversaciones ofreciéndoles para este efecto cien mil pesos desde luego, otros cien mil después que diesen principio a la revolución con más veinte cañones de campaña, municiones y otros auxilios ${ }^{41}$.

Así andaban las cosas en un ambiente en que a los puertos cubanos podían entrar embarcaciones francesas, dadas las buenas relaciones de aquellos momentos, cuando llegó la crisis de julio de 1797.

Los buques de guerra ingleses aparecieron, aunque no en el horizonte, sino frente a La Habana. Dos barcos americanos a principios de mes entraron en el puerto asegurando haber visto una división completa de barcos ingleses de guerra. Efectivamente, al día siguiente aparecieron en La Habana tres navíos y una fragata reconocidos por la marina desde el Castillo del Morro. Los buques de guerra eran un navío de 74 cañones, dos de 50 y una fragata con 40 puntos de artillería. Rápidamente Bassecourt organizó una junta con el Comandante General de Marina Juan de Araoz, el Comandante General de la Escuadra de Operaciones Gabriel de Aristizábal y el Intendente del Ejército José Pablo Valiente. Acordaron armar los navíos San Eugenio, Santa Isabel y San Ramón con todo lo necesario. Gabriel de Aristizábal necesitaba 600 hombres para subir a los barcos como refuerzo y, como no podía usar los veteranos de la guarnición porque no había suficientes, usó hombres de los Batallones de Pardos y Morenos de La Habana. Según Bassecourt estos eran "infelices pues todos ellos son artesanos y los que no están casados sostienen regularmente a sus madres y hermanas". El gobernador daba permiso por encontrarse en una situación tan crítica como era el bloqueo del puerto de La Habana. Era indispensable hacerse a la mar para romper el bloqueo en una acción de guerra desesperada. Dada la disposición de las fortalezas de La Habana los buques de guerra ingleses no podían acceder al puerto; luego, la única posibilidad que tenían era el bloqueo del acceso a este a una distancia prudente, lejos de la artillería insular. Los 600 milicianos embarcados fueron arengados con ardor para este servicio tan urgente, convirtiéndolos en guarnición de los buques de guerra. Los ingleses se

\footnotetext{
${ }^{39}$ AGS. SGU. Leg. 7.244, 76.

40 SERRANO Y SANZ, Manuel. El Brigadier Jaime Wilkinson y sus tratos con España para la independencia de Kentucky (años 1787 a 1797). Madrid: Tipografía de la Revista de Archivos, Bibliotecas y Museos, 1915.

${ }^{41}$ AGS. SGU. Leg. 6.929, 10.
} 
marcharon, volviendo a hacerse ver al día siguiente hasta un número de diez barcos, entre grandes y pequeños, aunque finalmente volvieron a desaparecer con tanto misterio como habían llegado. En esta situación Gabriel Aristizábal pidió a Bassecourt 50 artilleros y 200 marineros. Pocos días después entraba en el puerto de La Habana la división del navío "El Ángel", la fragata "Minerva" y buques mercantes procedente de Veracruz (México). Los buques de guerra se habilitaron con prisas para unirlos a los anteriores citados siendo la armada defensora compuesta por cuatro navíos, cuatro fragatas y un bergantín, con la idea de agregar a estas, las divisiones de las costas de Honduras y Veracruz, según había planeado Juan de $A_{r a o z}{ }^{42}$. Finalmente no se produjo ningún enfrentamiento y la armada inglesa observó, nada más. La nueva construcción de la fortaleza de la Cabaña, junto a la disposición de las demás, impedía una nueva invasión de La Habana como había ocurrido una treintena de años antes. Los militares ingleses no habrían tenido ninguna oportunidad, pese a la insuficiencia de tropas profesionales en La Habana.

Bassecourt narraba por carta a Manuel Godoy, a finales de julio de 1797 y con el susto en el cuerpo, el estado de las obras de fortificación necesarias ante la inminente invasión enemiga:

Las obras provisionales de profundizar el foso del recinto de esta plaza y de hacer el camino cubierto por parte de tierra desde la puerta de la Punta hasta la del Arsenal..." estaban en marcha, pero el Gobernador pensaba "...que por lo avanzado de la estación no debe recelarse expedición alguna contra esta colonia por ahora ${ }^{43}$.

Mientras tanto, como apenas podían llegar suministros españoles, Cuba compraba a los comerciantes de Estados Unidos ${ }^{44}$. También el Conde de Santa Clara pedía una dirección competente de los principales castillos de La Habana, inmiscuyéndose en los nombramientos. Ya había dispuesto en 1796 al teniente coronel del Regimiento de Infantería de Puebla, el coronel graduado Carlos de Urrutia, y al coronel de artillería F. Garcini "...la defensa del puesto principal del cordón de fortalezas de aquella plazd" ${ }^{\prime 4}$. Sin embargo, las comandancias del Castillo de La Cabaña y del Castillo del Morro estaban vacantes en 1798 y el gobernador instaba a que se cubriesen estas plazas. El Conde de Santa Clara promovía a estos cargos al coronel de Infantería del Ejército y subinspector del Batallón de Morenos Libres de La Habana, Antonio Seidel, o al comandante del Castillo de Jagua, el capitán Francisco José de Alvear, tanto para cubrir las vacantes o para las futuras de las fortalezas "de la Cabaña, Morro, Príncipe u otro de los que vaguen inmediatos a esta plaza" ${ }^{\prime \prime 6}$.

\footnotetext{
${ }^{42}$ Gobernador de La Habana sobre el avistamiento de buques ingleses. AGI. Estado, 1, no 44.

${ }^{43}$ El gobernador de La Habana sobre la defensa de aquella plaza. AGI. Estado, 1, no 40.

${ }^{44}$ AGI. Estado, 1, no 103.

${ }^{45}$ AGS. SGU. Leg. $6.877,23$, fol. $43 \mathrm{r}^{\circ}$.

${ }^{46}$ AGS. SGU. Leg. $6.877,23$, fol. $28 \mathrm{v}^{\circ}$.
} 


\begin{tabular}{|l|l|l|}
\hline $\begin{array}{l}\text { Guarnición que Bassecourt consideraba } \\
\text { indispensable para la defensa de la plaza de } \\
\text { La Habana y sus castillos (1797). [AGS. SGU. } \\
\text { LEG. 7.244, 24. AGI. Estado, 1, no 17]. }\end{array}$ & \multicolumn{2}{|l}{} \\
\hline $\begin{array}{l}\text { * Era necesario repartir una dotación de 25 } \\
\text { oficiales de artillería, más 500 soldados, cabos y } \\
\text { sargentos de artillería }\end{array}$ & Infantería & Caballería \\
\hline Plaza y castillo de la Punta & 3.000 & 200 \\
\hline Castillo del Morro, Batería del Sol & 600 & - \\
\hline $\begin{array}{l}\text { Castillo de la Cabaña, Batería de la Pastora, Cojimar } \\
\text { y Bacuranao }\end{array}$ & 3.000 & 200 \\
\hline Castillo de San Diego (alias no 4) & 50 & - \\
\hline Castillo de Atares & 200 & - \\
\hline $\begin{array}{l}\text { Fuerte del Príncipe, Torreón de la Chorrera y } \\
\text { Batería de Aróstegui }\end{array}$ & 1.600 & 200 \\
\hline Total: & 8.650 & 600 \\
\hline Total general: & 9.250 & \multicolumn{2}{|l}{} \\
\cline { 1 - 2 }
\end{tabular}

Fonte: AGS. SGU. LEG. 7.244, 24. AGI. Estado, 1, nº 17.

En febrero de 1799, Bassecourt disponía, ante la inminencia de la llegada de tropas enemigas inglesas, al Segundo Batallón del Regimiento de Milicias Disciplinadas de Infantería de La Habana (146 soldados, 3 oficiales) para auxiliar a la tropa destinada en los Castillos de la Cabaña y del Morro. Su Majestad aprobaba esta medida en mayo y las razones que esgrimía el capitán general era que las tropas de estas fortalezas eran insuficientes y los buques de guerra ingleses se aproximaban casi a tiro de cañón de las fortalezas para observarlos "...y como sería imprudencia no tenerlas bien defendidas, pues podrían los enemigos, con conocimiento de su débil guarnición hacer un pronto desembarco de noche e insultarlas' ${ }^{\prime 47}$.

Juan Procopio de Bassecourt tenía problemas externos pero también internos. Uno de ellos era especialmente pestilente, dado que el matadero municipal, cuando soplaba el viento del sur, obsequiaba con un aire irrespirable, además de vez en cuando no era extraño que "cuando introducían en la ciudad el ganado que se había de matar solían descarriarse algunos toros que enfurecidos con la grita del populacho causaban muchos daños' ${ }^{\prime \prime 8}$. El gobernador trasladó el matadero al paraje del Horcón (1797), construyendo una Casa de Baños en el lugar del antiguo matadero. Promovió también el establecimiento del Instituto de Ciencias Exactas y Naturales con un plan para instituir en el puerto de La Habana

\footnotetext{
47 "Defensa de Fortalezas con Milicias". AGS. SGU. LEG. 6.863, 14. 1799.

${ }^{48}$ VALDÉS, Antonio J. op. cit., p. 230.
} 
una escuela de pilotaje, persiguiendo una idea clara: "formar hombres útiles al Rey y a la Patria' ${ }^{\prime \prime 9}$. Ya que no les enviaban especialistas desde fuera, pretendía transformar a los insulares.

Entre el personal especializado existente en aquellos años estaba Vicente de Uriarte, cirujano que solicitaba en 1797 una subida de sueldo en su empleo en los cuerpos de guarnición fijos de fortalezas y hospitales de La Habana. Anteriormente, había sido hecho prisionero por los ingleses durante ocho meses (1779) siendo segundo responsable médico de la armada española en el Caribe y habiendo perdido todos sus bienes por aquel lance militar. El especialista del Real Colegio de Cirugía de Madrid se haría responsable del Primer Batallón del Regimiento de Milicias Disciplinadas de Infantería de La Habana, asistiendo a los enfermos en el Hospital Militar de San Ambrosio de La Habana ${ }^{50}$.

El Conde de Santa Clara podía haber agotado los cinco años de mandato en el cargo, pero tan solo estuvo tres que era lo mínimo que debía permanecer una vez nombrado. Las razones de su destitución fueron políticas, sin tener en cuenta la gran labor que estaba desarrollando en la defensa de La Habana, tanto por la organización de las tropas como por la consistencia en que quería establecer las fortificaciones. Se quejaba de que en un puesto tan destacado no tuviera mayor sueldo y, por ello, solicitaba una subida en 1798 "...pues de otro modo no será posible pueda subsistir en un país de que no podré salir con el decoro correspondiente y sin el sinsabor de dexar en él algunos acreedores' ${ }^{\prime \prime 1}$. El paso de Capitán General de Cuba a Capitán General de Cataluña debió ser un respiro para Bassecourt si atendemos la situación de peligro que describe en todo momento en sus cartas donde explica sus problemas ("falta de caudales, tropas, armas, municiones y pólvora para servir a la defensa de aquella posesión amenazada por los enemigos") y sentenciaba con una frase: "Me sobra el valor pero me faltan los auxilios ${ }^{\prime \prime 2}$. La llegada de unos complicados exiliados será lo que culminará, de la manera más secreta, con su sustitución al frente del gobierno de La Habana. Los pasajeros Luis Felipe de Orleáns, Duque de Orleáns (último rey de Francia, 1830-1848) y de sus hermanos Antonio Felipe de Orleáns, Duque de Montpensier, y Luis Carlos de Orleáns, Duque de Beaujolois, Ilegaban desde Nueva Orleans hasta La Habana con intenciones de viajar a Madrid, donde residía su madre. Esta situación produjo un conflicto diplomático con Francia, que se saldó con la destitución del gobernador de La Habana ${ }^{53}$. Una decisión política se camuflaba en la historiografía del siglo XIX señalando que el Marqués de

\footnotetext{
${ }^{49}$ AGI. Estado, 1, n० 32.

${ }^{50}$ AGS. SGU. Leg. 6.860, 6.

${ }^{51}$ AGI. Estado, 1, no 60.

52 No 1. Copia de carta del gobernador de La Habana, conde de Santa Clara, al virrey, marqués de Branciforte, interesándole la que había recibido de 15 de Octubre anterior del de Puerto Rico, contraída a manifestar la crítica situación en que se hallaba por falta de tropas, armas, municiones y pólvora, para la defensa de aquella posesión amenazada por los enemigos, y solicitando al primero el envío de pólvora para la plaza de la Habana y la de Puerto Rico. Habana, 5 de diciembre 1797. (Orizava, 30 Enero). No 2. Copia de carta de respuesta del virrey al gobernador de la Habana, expresándole haber hecho las posibles remesas de pólvora, y que continuará sus incesantes esfuerzos para repetir los envíos, siendo éste el único auxilio que puede facilitar como ya se hace cargo. (Orizava, 31 Enero). AGI. Estado, 27, no 23. Diciembre de 1797-enero 1798.

${ }^{53}$ AGI. Estado, 1, no 54.
} 
Someruelos, estando en La Coruña, recibió una orden reservada del gobierno para que embarcara de forma secreta, sin anunciarlo ni a su familia, hacia el Gobierno de La Habana "cuyo Gobernador el teniente general Conde de Santa Clara no había tomado para su defensa las medidas que se deseaban". El nuevo gobernador en secreto se subió a un mal bergantín cruzando el océano entre barcos enemigos, por lo que tuvieron que variar el rumbo en varias ocasiones, llegando a Trinidad y trasladándose por tierra, junto a dos esclavos, hasta que fue ayudado por un vecino que le prestó transporte. Presentándose al gobernador cesado por sorpresa y con unos pliegos, le sustituyó al instante. El cesado, lamentablemente, continuaría dos años y medio en la isla esperando la oportunidad para salir de ella ${ }^{54}$. Extraña situación de un militar ejemplar al servicio de Su Majestad que solo podía contemplar los tonos rojizos del atardecer que tomaba La Habana. A mediados del siglo XX se justificaba su destitución porque "la avanzada edad de Santa Clara hizo temer que le faltaran energías para continuar desempeñando su cargo"55, ¿a los tres años no valía para el puesto? No mucho tiempo después de su destitución (1838), se afirmaba que:

...el gobierno de Santa Clara hubiera sido sin duda muy ventajoso a La Habana, si se hubiera siquiera extendido a los cinco años regulados a cada gobernador, pero apenas iba tomando conocimiento de los defectos del país, y discurriendo sus mejoras, cuando fue removido con dolor de todos los habitantes, de quienes se hacía amar irresistiblemente, dejando su bando de buen gobierno ${ }^{56}$.

El Marqués de Someruelos, Salvador de Muro y Salazar, tomaba posesión en mayo de 1799 tras los grandes esfuerzos de Bassecourt por blindar la plaza que le tocó defender. Heredaba los problemas como gobernador de La Habana, Luisiana y Florida. Entre sus principales actividades, el nuevo residente se volcó en comprobar la situación de las obras de las fortificaciones en Santiago de Cuba, Nueva Orleáns, Pensacola, Florida y La Habana ${ }^{57}$. En 1799 había problemas en las obras de fortificación de Pensacola (Florida) porque no había suficientes operarios para realizarlas por lo que el ingeniero responsable pretendía suspenderlas ${ }^{58}$.

La actividad de Bassecourt al frente de La Habana nos muestra la gran importancia que tuvo la arquitectura militar y la combinación de tropas militares

\footnotetext{
${ }^{54}$ DE LA PEZUELA, Jacobo. Diccionario Geográfico, Estadístico e Histórico de la Isla de Cuba, Imprenta del Banco Industrial y Mercantil, Madrid, Tomo IV, p. 561, 1867.

${ }_{55}$ ALCÁZAR MOLINA, Cayetano. "Los Virreinatos en el siglo XVIII", Historia de América y de los pueblos americanos. Tomo XIII, Barcelona-Buenos Aires: Salvat, p. 194-195, 1945.

${ }^{56}$ Memorias de la Sociedad Patriótica de La Habana. La Habana: Oficina del Gobierno y Capitanía General, Tomo VI, p. 90, 1838.

${ }^{57}$ AGS. SGU. Leg. 7.246, 43.

${ }^{58}$ Documento que da cuenta de la falta de operarios que hay en Panzacola para el progreso de las obras de fortificación y de lo que ha practicado sobre esto, antes de suspenderlas como propone el ingeniero Director. La Habana, 1799. AGI. Santo Domingo, 2.567, nº 29.
} 
profesionales con las locales en la defensa de La Habana como punto clave en el tráfico comercial americano. La enorme complejidad del mantenimiento económico y estratégico de aquellas plazas de ultramar supuso un enorme esfuerzo de los ingenieros militares españoles en el siglo XVIII que es un aspecto relevante de la historia del Caribe y de América. Se abordan en este artículo las vicisitudes del gobernador Bassecourt al frente de su mandato (1797-1799) en donde se puede observar su actividad al mando de la plaza española más importante de la América española. Pese a los enormes problemas de gestión, aquellas fortificaciones del Caribe aseguraron el dominio de unas tierras lejos de la corte que, finalizando el Siglo de las Luces, mantenían vivo el dominio de la Monarquía hispánica en América. Unas tierras que se emanciparían a lo largo de la compleja etapa política española del siglo XIX. Las decisiones políticas equivocadas marcaron el rumbo hacia la desmembración de los territorios que un día encontró Cristóbal Colón para unir a dos mundos diferentes.

\section{Sobre o autor}

Juan de Ávila Gijón Granados é Doutor em História Moderna pela Universidade Complutense de Madrid (2008), onde defendeu a tese intitulada "A Casa de Bourbon e as Ordens Militares no século XVIII (1700-1809)". Professor convidado do Instituto de História (CSIC), em 2006, desenvolveu vários projetos de pesquisa, além de seu trabalho como professor de história do Departamento de Educação da Comunidade de Madri (Espanha).E-mail: easystoria@gmail.com

Artigo recebido em 14 de janeiro de 2014. Aprovado em 25 de junho de 2014. 